\title{
Learner-Centered Teaching: A Case Study of its Implementation in Physics and Chemistry Classes in Moroccan High Schools
}

\author{
Mohamed Merouane El Hammoumi, \\ Bio-Geosciences and Material Engineering Laboratory «LBGIM » \\ Ecole Normale Superieure, Hassan II University, Casablanca, Morocco \\ Said Bakkali, \\ Analytic and Molecular Chemistry Laboratory (LCAM), Multidisciplinary \\ Faculty, Safi, Cadi Ayyad University, Marrakesh, Morocco \\ Safaa El Youssfi, \\ The American Language Center and Moulay slimane High School, \\ Fes, Morocco
}

Doi:10.19044/esj.2020.v16n22p271 URL:http://dx.doi.org/10.19044/esj.2020.v16n22p271

\begin{abstract}
Following the international call of the learner-centered approach, the Moroccan educational system has undergone a paradigm shift in teaching methods. Physics and chemistry textbooks used in Moroccan high schools highly valorise learning strategies development, self-directed learning, and discovery learning, which promote the learner's autonomy. This study provides an overview of the learner-centeredness principles, and it is based on data collection which is accomplished using a questionnaire administered to 35 physics and chemistry high school teachers. It focuses on analysing the teachers' attitudes towards this approach. The study shows that majority of the teachers are motivated towards implementing the learner-centered approach, but very few of them rely on both teacher and student-centered teaching simultaneously to cater for students' learning needs. This paper recommends the use of active learning to cater for a successful educational system.
\end{abstract}

Keywords: Student-centred approach, Active learning, Attitudes, Lifelong learning, Teaching physics and chemistry

\section{Introduction}

The realization of the importance of the learner as an essential component of the teaching learning operation was at the origin of the development of approaches to teaching, which puts the learner at the centre. This concern with the learner may be traced back to what was called the 
"humanistic" movement in education which was prevalent during the $1960 \mathrm{~s}$ and the 1970s. The rationale behind this movement was that the learner is a whole human being whose needs, emotions, attitudes, values, feelings, and motivation are to be considered as primary objectives before the cognitive ones. According to Constructivist learning, 'learners construct their own meaning...manipulate, discover, and create knowledge' (Bhattacharjee, 2015, p. 66). In addition, Humanism highlights the development of the learner as a whole and not solely the development of his/her cognitive structures.

The influence of the humanistic movement has led to the development of a number of approaches and methods such as the task-based approach, cooperative learning, problem-based learning, the differentiated pedagogy, etc. These approaches and methods emphasize a shift from concern with the syllabus, the content, the methodology, the teacher, and the assessment of the learner and the process of learning.

The ultimate focus of this study is on the teachers' attitudes towards the learner-centred approach. This study falls into two major parts. The first part gives a tentative definition of how the learner-centred approach is provided, while also considering some of the major principals of this approach. The second part sets out to examine the extent to which teachers welcome or decline the idea of adopting this approach in the Moroccan classroom. This is achieved by analysing what has been gathered through a questionnaire administered to secondary school teachers.

This study does not attempt to promote any teaching methodology. However, it highlights the potentials of the student-centered approach, which is aimed at not only promoting effective teaching, and deep, pervasive and sustainable learning, but also increasing motivation and greater retention of knowledge.

\section{Learner-Centered Approach: Definition}

Learner-Centeredness came as a call for educational reform. It is an approach that tries to correct shortcomings in traditional teaching trends which viewed learning as a matter of habit formation and considered the teacher as a source of knowledge. This shift in the definition of teaching and learning has important implications for the role of the learner, the teacher, and the materials. According to the learner-centered approach, the learner is no longer considered as a recipient, but as an active participant who is very much involved in the teaching/learning operation. Teachers, on the other hand, adopt the role of guides and facilitators instead of being at the centre of the class. Authentic materials are also tailored to suit the learner's needs.

The student-centered approach advocates active learning where students solve problems, hypothesize, discuss, elaborate, debate, and brainstorm. Cooperative learning is a basic method in this approach where students work 
in teams to solve problems or work on projects. In this respect, spaces are created during class time where spontaneous learning can occur in order to provide opportunities for autonomous and self-directed learning experiences (Brown, 2003).

This comprehensive definition states all the basics of the learner-centered approach. It highlights the benefits of the approach which resides in the contribution of developing the learner as a whole and giving more value to the socio-cultural, personal, and psychological specificities of the learner. This was marginalized by previous approaches to teaching and learning.

Learner-Centeredness, as an approach, is based on the assumption that stronger retention of learning is fostered when the teacher creates a relaxed and non-threatening psychological atmosphere where all students are relaxed and engaged. This is achieved by improving pedagogical practices and promoting child-friendly, learner-centered, and experiential school atmosphere (Subedi \& Shrestha, 2020, p.3). Hence, the learner's cognitive and affective needs are met and his/her favorable attitudes and motivation are fostered while the inhibitions are dissolved.

Learner-Centeredness is an approach that engages students in activities that trigger their discovery and critical thinking skills. Also, it fosters students' autonomy, self-direction, self-assessment, self-learning, and control over choices of activities, learning methods, and timing (Harizaj, 2017, p.127).

The main concern of this approach is to tailor teaching as far as possible with the learner's real-life needs, values, personal experiences, capabilities, interests, and background.

\section{Learner-Centered Approach: Major Principles \\ Learner's Needs}

The needs of a learner (affective, cognitive, social and psychomotor) represents the gap between what the learner aims to get out of the learning experience and his or her current state of knowledge, skill, and enthusiasm (Noessel, 2003). This is because each student is unique and brings to the learning situation his or her own different learning style and strategies, knowledge and skills set, past experiences, and motivation (Dick, Carey, \& Carey, 2004). Therefore, on the first day of class, the teacher should collect information about the students' knowledge, attitudes, skills, learning styles, and needs. This allows the teacher to know his students better and to develop a community inside his/her class. It also helps to plan what to teach and how to teach.

Students, therefore, have specific learning needs. This is stated by Touli et al. (2015, p.2246) who claimed that 'in the teaching of science in general and chemistry in particular, the main mission is to help students develop an understanding of the natural world and its phenomena from a 
scientific approach'. They also have professional/vocational needs. This refers to what the learner has to do with what he learnt after he has learned it. Thus, the question to be asked, in this respect, is: who is the best person to identify the learner's needs? The groups most concerned with the definition of needs may be the learners themselves, teachers, administrators, and parents. Although the issue of who should define the learner's needs is a subject of debate, it is now obvious that the learner should contribute in one way or another to define his needs. Therefore, teachers should help the learner develop the ability to realize his/her needs. For the learner-centered approach, teaching is put at the service of the students' needs and the discovery of his or her needs, which are kept at the center of the teaching learning operation.

\section{Learning Strategies and Study Skills}

More focus is being directed towards teaching the learner efficient learning strategies and study skills in order to foster his/her independence, responsibility, and lifelong learning. As stated in Education Corner (2020), there should be focus on teaching how to do library research and projects, how to take notes, how to operate in group work to share insights with one another, how to do field work research, how to carry out independent study, how to write a report or a research paper, and how to use laboratory materials. Learning about laboratory skills will make students rely on themselves in the long run. Thus, concept mapping is considered an essential learning strategy which students can use to optimize knowledge, retention, and to inculcate thinking skills (Osman et al., 2013, p.679). This is because studies have shown that through this meaningful learning, students are able to retain input that is visually presented (op.cit). Concept mapping and brainstorming are regarded as vital tools that enable the learner to trigger his or her meta-cognition and make use of prior and existing knowledge as a basis to build upon new knowledge (Gurlitt \& Renkl, 2007).

\section{$\underline{\text { Assessment }}$}

According to the learner-centered approach, evaluation is viewed as a means that would help both learners and teachers. The former to learn from their mistakes and the latter to assign remedial work and plan lessons on what the students need, and not something that threatens or criticizes them. Selfassessment is to be done by the learner on a regular basis, which helps him/her to evaluate his/her progress. It also allows the learner to keep track of his/her progress. Moreover, exams are to be differentiated to match students' differences. This is because there are some students that do well in open-ended questions, whereas others do better in close tests. This, however, depends on whether they have convergent or divergent thinking. The new trend highlights the importance of divergent thinking in the student in order to develop his/her 
creative abilities. Creativity and innovation is promoted by this approach since they make our world a better and an exciting place, where our children should be taught to be happy and successful human beings (Solidum, 2018).

Another point which is worth analysing here is that teachers who adopt learner-centeredness valorise group evaluation. According to Astin (1996, p.126), "the strongest single source of influence on cognitive and affective development is the student's peer group ... the study strongly suggests that the peer group is powerful because it has the capacity to involve the student more intensely in the educational experience". Thus, collaborative learning and testing should be encouraged by assigning group projects where students can work collaboratively to attain common objectives.

\section{Teacher's Roles}

The learner-centered approach implies different roles for the teacher. The teacher is viewed as a skilled manager, a facilitator, and an overall organizer of activities (op.cit). He should be able to predict which student gets along with each other. He is a resolver of conflicts and is responsible for setting-up suitable learning conditions. The teacher moves from being a sage on the stage to a guide on the side. His role resides in building a harmonious social community in and outside the classroom where good students help weaker ones (op.cit). The teacher, in this approach, cannot assume the role of a knowledge transmitter, but can only act as a knowledge facilitator. This is done to help learners realize their learning goals themselves, discover hypotheses, test them, and accept or discard them. The teacher's role, in this discovery process, is that of a helper, a planner, a guide, and a shaper of the students' achievements. According to Moustafa et al. (2013, p.418-419), in a class setting, "the teachers' role is to encourage and accept student autonomy and create a comfortable atmosphere for student expression".

Consequently, teachers should structure his/her lesson in a nonchallenging way. The lesson is to be divided into manageable chunks (gradation) and each chunk is to be positively reinforced. The teacher should also help students work and learn independently. Teachers enable students to become problem solvers by equipping them, through scaffolding support, with the necessary skills that would enable them to lead their own learning (Dysart, 2019). However, the learner-centered approach does not make the teacher invisible. On the contrary, the teacher has to be more active in order to get more prepared for class. The teacher should also be very creative and humanistic. 


\section{Learner's Role}

The learner-centered approach is aimed at developing in each learner a sense of responsibility, autonomy, and self-reflections for his/her lifelong learning.

Learner-centeredness places the learner at the center of the teaching learning operation. The voice of the learner is also heard, and it valorises his/her active participation in the learning process. Group work, group discussion, and students' projects are instances of opportunities where students contribute in the course process. These kinds of opportunities given to the learner should be geared towards problem solving and decision making that would foster students' autonomy and independence.

Cooperative learning is to be adopted in the class. Nevertheless, an emphasis on individualized learning is significantly important since it is only the learner who can learn for him/herself. This is because the other students can only help the learner to reach the final goal.

Therefore, students should be trained to be autonomous. Nunan (1988, p.3) highlighted different tips that would help teachers implement learnercenteredness. Thus, the tips for students' autonomy are as follows:

- Provide learners with efficient learning strategies

- Assist learners to identify their own preferred ways of learning

- Develop skills needed to negotiate the curriculum

- Encourage learners to set their own objectives

- Encourage learners to adopt realistic goals and time frames

- Develop learners' skills in self-evaluation

In addition, the learners should be equipped with a set of different learning strategies that would help them learn effectively in different situations. The learners should also contribute in negotiating the curriculum, setting up their goals, as well as controlling, guiding, and self- assessing their learning.

Moreover, the learner plays an active role in selecting materials according to his/her needs and skills. Here, the teacher's role in controlling the materials selection is reduced to the minimum. The learner, therefore, is given real choices concerning the content of the course and nothing is being imposed on the students. Choices are made according to the students' interests and personal needs.

\section{Materials/Tasks/Curriculum}

Tasks are to be in pairs or groups to encourage students' interactions, which helps learners to get engaged in negotiating, checking, revising and constructing meanings, and solving problems ( Rakab, 2016, p.83). 
These tasks should be authentic, stimulating and varied to match students' different learning styles and encourage their meta-cognition. The curriculum should also be alike. The curriculum and materials should encourage students' critical thought, their capacity to form hypotheses, test them, and find right solutions. Subsequently, their ability to ask questions, to research, and to judge should also be encouraged. Moreover, curriculum development, according to learner-centered approach, is a decision made collaboratively between teachers and students. Learners are no longer in the periphery but are active contributors in making decisions on teaching methods, course content, and assessment (Nunan, 1989, p.9).

\section{The Teaching of Physics and Chemistry in Moroccan High Schools}

In Morocco, like in many other countries, teacher-centered approaches are predominant in our high schools. 'The teacher is primarily responsible for the transmission of knowledge' (Touli , op.cit). Thus, students' active learning and engagement is not given much importance. This shows the low level of students' motivation towards this subject matter. In other words, they are not considered as the centre of the learning process but as the recipient of knowledge. Therefore, their retention is very low as well as their performance.

This might be due to the lack of necessary teaching materials and facilities and the adoption of traditional approaches to teaching (lecturing). The students' learning strategies can also be a factor that contributes to the failure or the success of learning physics and chemistry. This implies that 'students tend to memorize what they are taught without conceptual understanding' of the subject (Uwizeyimana, 2018, p.2). In problem-based activities, some physics teachers write formulas and manipulate mathematical equations to find the final solution without giving the opportunity to students to explore physics concepts by hypothesizing, experimenting, and drawing conclusions (Elby, 2001). To optimize students' achievements and performance in physics and chemistry, the above factors should be given more attention in order for students to develop their critical thinking and lifelong learning.

Furthermore, the goal of learner-centeredness is to equip students with efficient learning strategies, creative and critical thinking, and problem solving and decision making abilities that would make them actively involved not only in the teaching learning operation, but also outside the class as lifelong learners.

\section{Methodology of Data Collection}

A questionnaire was used to obtain information about the attitudes of secondary school teachers towards learner-centeredness, and the extent to which active learning is adopted in Moroccan classrooms. Thirty-five (35) 
copies of the teachers' questionnaire were sent in Google forms via whatsapp and email to teachers from different high schools in Fes and Tangiers. However, only 27 teachers responded.

The first thing to consider before making the questions is to ascertain the format of the questions. After then the order of the questions should be arranged in the questionnaire for maximum results. For the format of the questions, there are two basic types: open-ended questions and closed-ended questions.

The questionnaire consists of three sections. An opening statement informs the respondents about the purpose of the questionnaire and the guarantee of confidentiality of the information provided. The first section collects information about the respondent's background such as the age, sex, and degree, using closed questions. The second section consists of a question that elicits data about the teacher's attitude towards learner-centeredness. The third section shows whether physics and chemistry teachers adopt this approach in their classroom and use techniques that cater for students' participation and engagement in the teaching learning process. The questions were arranged in a way that gives maximum results. Most questions were close-ended since they can be more reliable and of great use analytically. A quantitative analysis of the data was carried out. Focus was given mostly to striking figures that are considered more important for this research.

\section{Findings}

\section{Respondents' Background Information}

This section provides some background information about the respondents. It is made up of three items, and the first item provides information about the age of the respondents. The pie chart clearly shows that a high percentage of respondents are more than 45 . This means that they must be senior teachers.

Figure 1. Age

Age

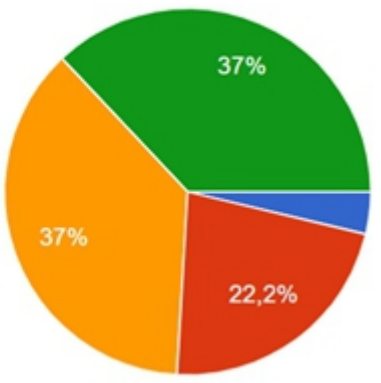

Below 25

Between 25-35

Between 35-45

Over 45

The second item was designed to know the percentage of male and female respondents. 
Figure 2. Sex

Sex

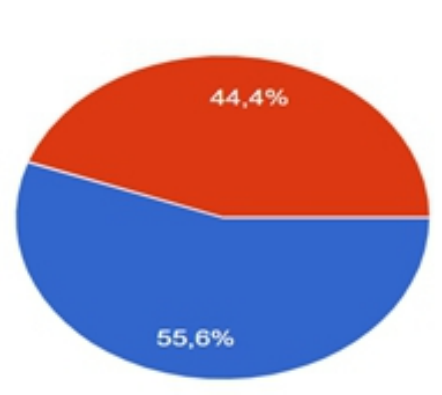

Male

Female

The third item was designed to acquire information about the degree of the respondents. It is clear in Figure 3 that more than half of the respondents have a deep academic knowledge and have developed strategies and behaviours to help meet pedagogical demands.

Figure 3. Degree

Degree

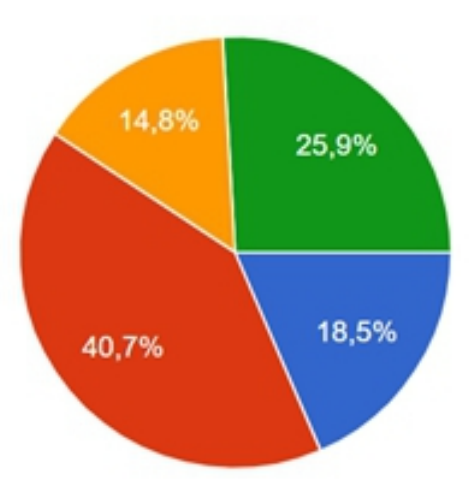

BA

MA

PHD

Other

Figure 4. Teacher's attitudes towards the learner-centred approach

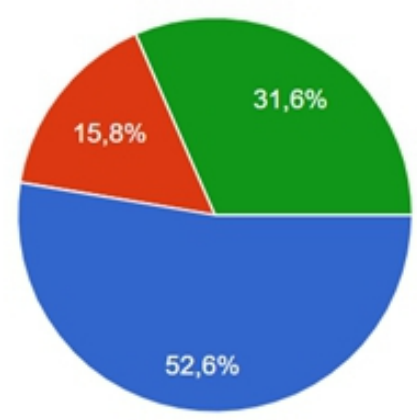

That's excellent

That's all the same

That's not rewarding at all

That's a pretty good idea

I'm not sure I can go for it 
The figures in the above pie chart indicate that majority of the respondents support learner-centeredness. They encourage the full implementation of this approach in Moroccan classrooms. Also, $31.6 \%$ are of the opinion that this approach is a pretty good idea since it assures both the learning and the teaching operation and develops students' self-confidence and responsibility for their own learning. Learner-centeredness for some teachers means giving opportunities to students to feel important in their classrooms and to develop lifelong skills. Only a few (15.8\%) of the respondents stated that it cannot be entirely implemented because the need of a teacher for clarification or guidance is necessary. This is because the classroom is the only opportunity for students to learn physics and chemistry concepts. They argue that it is hard to achieve this approach fully in a context like ours because the classroom reality has many hindrances such as large classes, lack of teaching materials, and the length of the programme. They claimed that they adopt an eclectic approach where they rely on the traditional methods as well as the active ones simultaneously. They also stated that learner-centeredness as an approach is, thus, too perfect for the Moroccan classroom.

Figure 5. The attitudes of teachers towards some of the principles of this approach

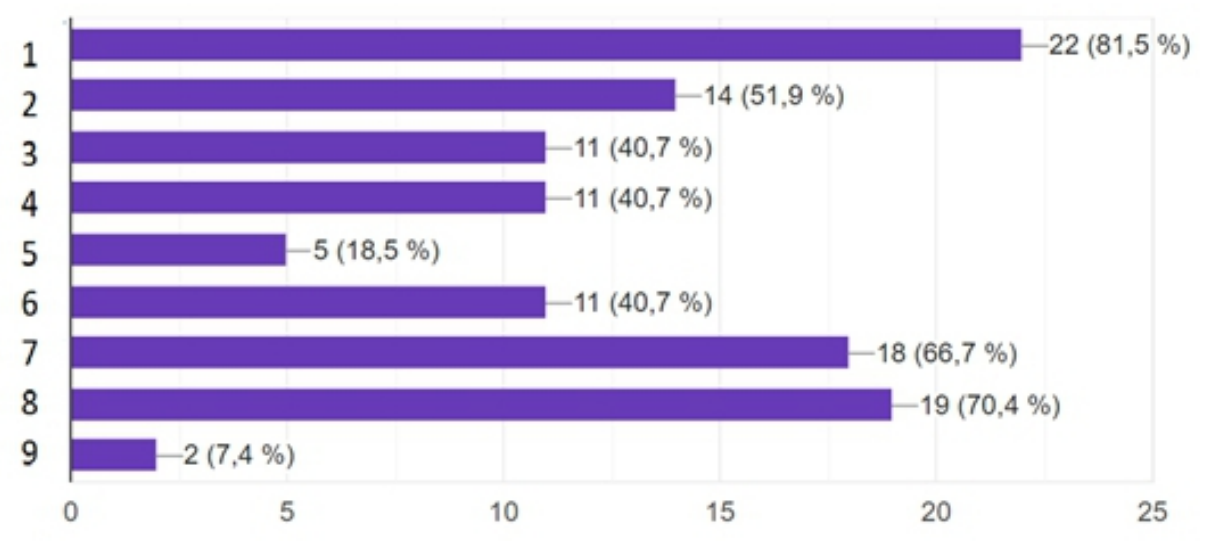

1. Students should know how to use the materials in class and the lab

2. Students should be the main focus in class

3. Students should be able to identify their learning needs

4. Students feel more secure in the presence of the teacher

5. They teacher should be the only authority in class

6. The teacher should provide guidance and help in class

7. Students should discover knowledge by themselves and not take everything from the teacher

8. Stimulations, games, and oral presentations should be used in class

9. The teacher should be the only source of knowledge 
The above figures reinforce what has already been argued in the previous item. The teachers' attitudes towards the students' choice of activities, discovery learning, the teacher's limited role, and the students' needs are very positive. This shows how optimistic the teachers are towards this approach.

Very few teachers feel that this approach threatens their status since, according to the learner-centred approach, the teacher should be on the side. Five (5) teachers see that the full presence of the teacher is very much needed. In this case, the teacher needs to clarify almost everything. If this is not done, those students would give up, adopt negative attitudes, and lose motivation in the subject. More so, other teachers stated that the students are used to getting everything from the teacher since primary school. Therefore, they feel more secured when the teacher provides them with instructions, clarifications, comprehensive explanation, and sometimes answers.

\section{Learner-Centeredness in Moroccan Classrooms}

This section aims at analysing the extent to which the Moroccan classroom is learner-centred. The bar graph below clarifies this argument.

Figure 6. Learner-centeredness in the Moroccan classroom

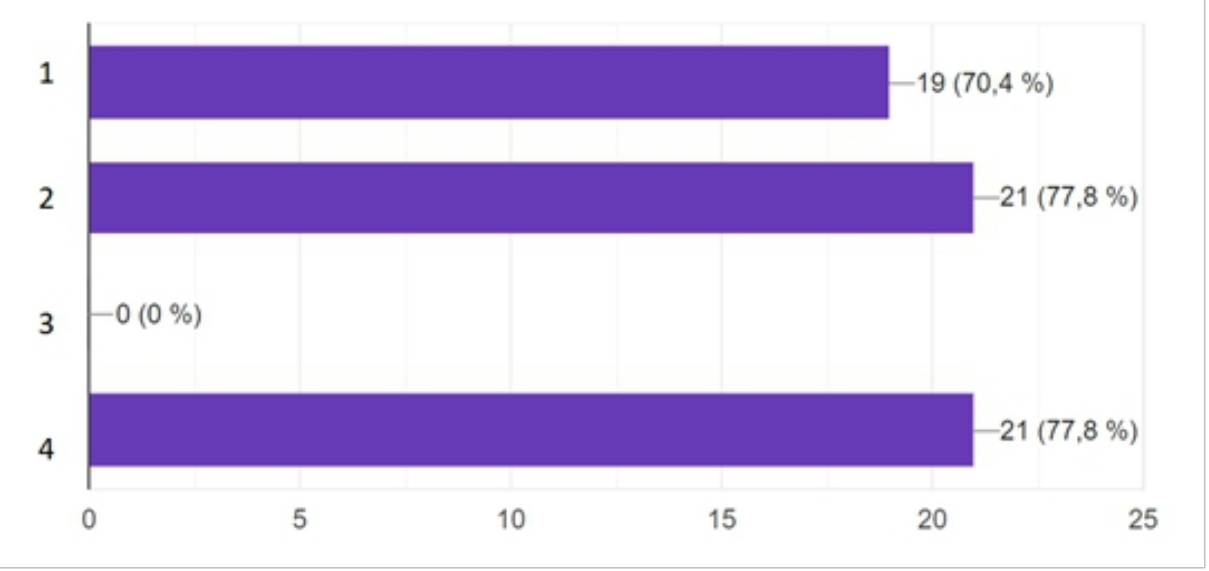

The teacher helps students in the following ways:

1. To achieve independence and responsibility for their own learning

2. To work outside the class

3. To be receptive and get knowledge only from the teacher

4. To cooperate with friends on a given task 
Figure 7. Techniques used in the Moroccan classroom

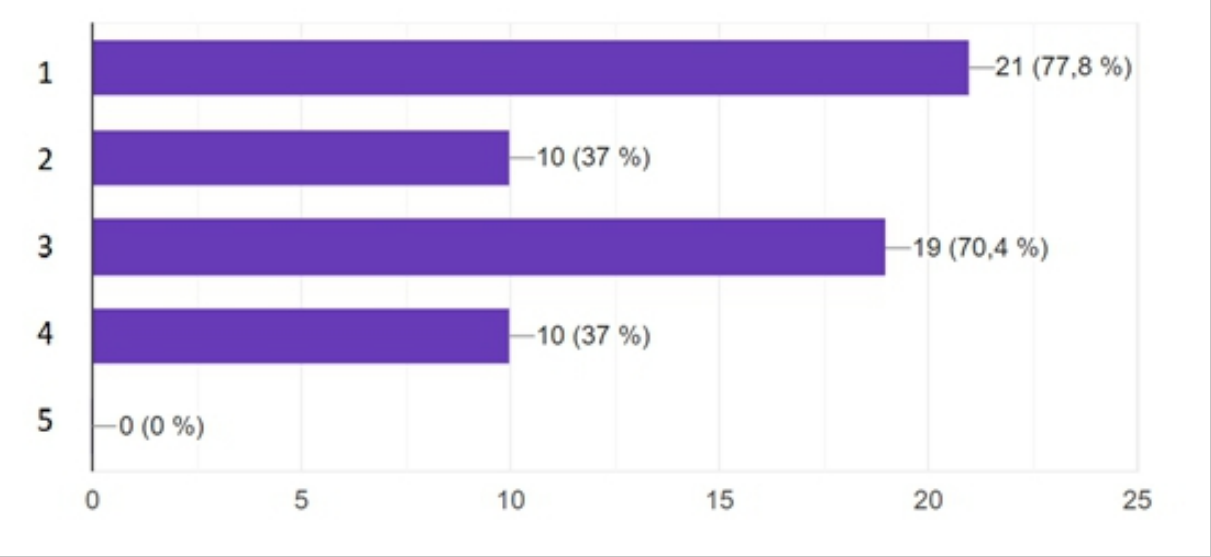

The teacher tries to do the following:

1. Give opportunities to students to express themselves

2. Provide activities and permit students choice

3. Guide students towards achieving their goals

4. Control everything in the class

5. Use the same method and activities in teaching

Figure 8. Student-centred activities

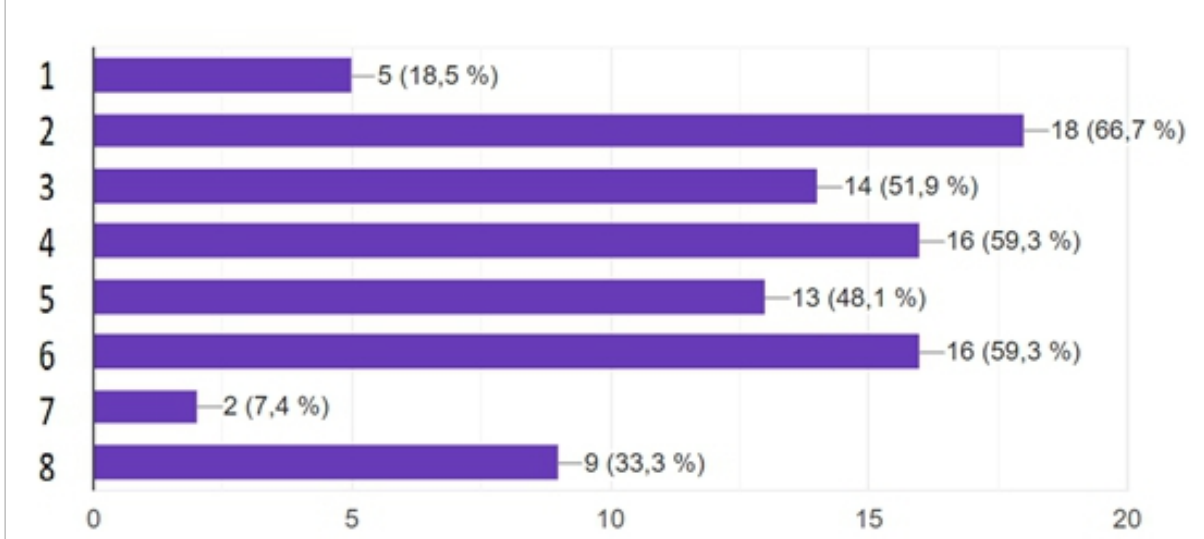

Activities teachers use in the class include the following:

1. Brainstorming

2. Experiment simulations

5. Individual work

3. Lab experiments

4. Debate and discussions

6. Group work

7. Concept mapping

8. Note-taking

The figures in the above graphs show that majority of the respondents implement this approach in their class. They advocate that it is due to the big shift of paradigms which the Moroccan educational system has undergone lately. In Morocco, there is a great emphasis on implementing active methods that help students achieve their autonomy, self-confidence, and responsibility 
for their own learning. Most teachers (77.8\%) assign take-home projects (individual work), give chances to students to express themselves in debates and discussions, encourage cooperative learning especially when they are working in the lab, and guide students towards achieving their goals. Most teachers $(77.8 \%)$ cater for students who need help to understand an experiment especially in the case where materials and equipment in the lab are short in supply. In this respect, most teachers use stimulations through videos. None of the respondents, however, assist students to be receptive and acquire knowledge only from the teacher. All teachers, even those (37\%) who control everything in class, believe that students should be engaged in developing cognitive skills that enable them to elicit knowledge and bring about better learning outcomes. 10 teachers $(37 \%)$ claim that classroom management is a real challenge for the teacher. This is why if a teacher gives the leading seat to students, they might lose their significant place and role in class. Brainstorming (5 respondents) and concept mapping ( 2 respondents) are not as famous as other techniques. A teacher claimed that he is not familiar with these techniques and he has never benefited from any training on them. A respondent believes that concept mapping is an efficient visual strategy that is difficult for physics and chemistry teachers to use. Also, learners claim that it requires a strong cognitive process where the learner tries to construct logical meaningful content and ultimately develop high order scientific thinking skills. The respondent further added that Moroccan teachers and students are not well-trained to do that.

\section{Conclusion and Recommendations}

This study clarifies how teachers show their motivation towards implementing the learner-centered approach. Nonetheless, very few teachers rely on both traditional and active methods simultaneously to cater for students' learning needs. The results presented by Muganga and Ssenkusu (2019) revealed that majority of students believed that learning occurred through teacher-centered rather than student-centered methods.

The data collected reveals how crucial the learner-centered approach is. Majority of teachers highlight the benefits of implementing this approach. They believe that this approach encourages active, cooperative, and lifelong learning. It also highlights students' autonomy, creativity, critical thinking, and self-reliance which are $21^{\text {st }}$ century skills that are tremendously important more than ever before. The same results were found by Aghris (2018). She states that the outcome of this study confirmed that both Moroccan teachers and students have generally positive attitudes toward the implementation of the learner-centered approach with the hope to improve the context of learning and education in general. However, very few of them opined that it is new to both teachers and students and they feel confused while following it. The latter 
claimed that the Moroccan educational system is an examinations-oriented system where grades are all that matters. In addition, the syllabus is overloaded and the scarcity of the educational facilities and equipments limits the teachers' creativity and adoptions of discovery and active learning.

It is worthy to note that brainstorming and concept mapping are key strategies that are important in the teaching of physics and chemistry. The instructors should be well-informed and trained on these techniques since they help to improve students' long-term memory and knowledge retention. They also trigger the learner's meta-cognition and make learning meaningful.

Therefore, the success of the educational system in Morocco is truly dependent on how teachers and students are fully exposed to modern teaching methods and techniques. Future pre-service and in-service training should also give considerable importance to training teachers on how to use brainstorming and concept mapping to guarantee long-term memory and effective teaching learning process. Students should also be prepared from primary school to create concept maps, use the brainstorming technique, and discover how they both function in developing new meaningful concepts, high order cognitive and meta-cognitive skills, and connections. They are the perfect visual strategies that give students a solid background to start from the known to the unknown and, therefore, help them understand complex concepts and link them to prior knowledge. This would be a powerful basis from where students would proceed until they reach high school and college.

Conclusively, this study provides opportunities for future research to evaluate the use of active teaching techniques in Moroccan classrooms and to investigate its impact in developing students' engagement in the learning process as well as their intellectual scientific skills.

\section{Acknowledgements}

I would like to express my sincere gratitude to high school physics and chemistry teachers whose contributions in the data collection was highly appreciated.

\section{References:}

1. Aghris, A. (2018). 'Promoting the Learner Centered Approach in the Moroccan EFL Classroom' in http://morcenet.org

2. Astin, A.W. (1996 ). 'Involvement in Learning Revisited: Lessons we have learnt', Journal of College Student Development, 37 (2) pp.126.

3. Bhattacharjee, J. (2015). Constructivist Approach to Learning- An Effective Approach of Teaching Learning, Volume-I, Issue VI, PP 66.

4. Brown, K. L. (2003). From teacher-centered to learner-centered curriculum: Improving learning in diverse classrooms. Education, 124, 49-54. 
5. Dick, W. O., Carey, L., \& Carey, J. O. (2004). The Systematic Design of Instruction. Boston: Allyn \& Bacon.

6. Dysart, D.C. (2019). 'The importance of Instructional Scaffolding' in https://www.teachermagazine.com.au/articles/the-importance-ofinstructional-scaffolding

7. Education Corner. Chemistry Study Skills Guide. In www.educationcorner.com/chemistry-studyskills-guide-html, 2020.

8. Elby, A. (2001). Helping Physics Students Learn About Learning. Physics Education Research, Am. J. Phy. Suppl., 69(7): S54-S64.

9. Eggleston, T. \& smith, G. ( 2002). 'Building Community In The Classroom Though Ice breakers And Parting Ways'. In www. Nurturinpotential.com

10. Galan, M. \& Maguire, T. ( 2002). "Classroom Management" Humanising Language Teaching, Issue 2.

11. Gurlitt, J. \& Renkl, A. (2010). Prior Knowledge Activation: How Different Concept Mapping

12. Tasks Lead to Substantial Differences in Cognitive Process Learning Outcomes and Perceived Self-efficacy, Instructional Science, 38 (4) 417- 433.

13. Harizaj, M. \& Hajrulla, V. ( 2017). 'Fostering Learner's Critical Thinking Skills in EFL:

14. Some Practical Activities' European Scientific Journal edition Vol.13, No.29, pp $126-133$.

15. Moustafa, A., Ben-Zvi-Assaraf, O., \& Eshach, H. (2013). Do junior high school students perceive their learning environment as constructivist? Journal of Science Education and Technology, 22(4), 418-431.

16. Noessel, C. (2003). Free range learning support. Interaction Design Institute, in www.interaction-ivrea.it/theses/2002-2003/cnoessel/need.htm.

17. Nunan, D. (1998). Designing Tasks For The Communicative Classroom. Cambridge : Cambrige University Press.

18. Osman et al. (2013). Concept Mapping In Chemistry Lessons : Tools For Inculcating Thinking Skills In Chemistry Learning. Journal Of Baltic Science Education, Vol. 12. Issue 5 pp. 679.

19. Rakab, M.B. (2016). Pair-Work and Group-Work Activities: Myth or Reality?, International Journal of Educational Investigations, Vol.3, No.6: 82-100.

20. Muganga, L. \& Ssenkusu, P. (2019). 'Teacher-Centered vs. StudentCentered' in https://www.researchgate.net/publication/336117384 
21. Solidum, R.A. (2018). 'The Importance of Creativity and the Student Centered-learning Methods in Contemporary Education' Revista Educatiei.

22. Subedi, R. \& Shrestha, M. (2020). 'Student Friendly Teaching and Learning Environment:

23. Experiences from Technical Vocational Educational Training Schools in Nepal' European Journal of Educational Technology 3(1): 1-13.

24. Toule et al. (2015). Teaching And Learning Of Experimental Science: The Case Of Chemistry In Secondary Qualifying Morocco, Procedia Social and Behavioral Sciences 191 : 2246 - 2249.

25. Uwizeyimana, D. (2018). The Impact Of Teaching Approaches On Effective Physics Learning: An Investigation Conducted In Five Secondary Schools in Rusizi District, Rwanda. Rwandan Journal of Education, Volume 4 -No 2. pp $4-14$. 